\title{
INFLUÊNCIA DO DESCARTE INVOLUNTÁRIO DE MATRIZES NO IMPACTO ECONÔMICO DA MASTITE EM REBANHOS LEITEIROS
}

\author{
Influence of involuntary of matrices culling on the economic impact of mastitis in dairy herd
}

\author{
Fabiana Alves Demeu ${ }^{1}$, Marcos Aurélio Lopes ${ }^{2}$, Geraldo Márcio da Costa', \\ Christiane Maria Barcellos Magalhães da Rocha ${ }^{1}$, Glauber dos Santos ${ }^{1}$, Agnelo Franco Neto ${ }^{1}$
}

\begin{abstract}
RESUMO
Objetivou-se com esta pesquisa, analisar e quantificar a influência do descarte involuntário de matrizes no impacto econômico da mastite em rebanhos leiteiros. A pesquisa foi realizada por meio de simulação no sistema computacional CU\$TO MASTITE, considerando rebanhos leiteiros com taxas de descarte de 2,4 e $6 \%$. Foram considerados como prevenção as despesas com monitoramento (cultura e antibiograma, contagem de células somáticas no tanque e contagem de células somáticas individuais), pré e pós dipping, vacinação, tratamento de vacas secas e manutenção de ordenhadeira. Como medidas curativas consideraram-se os tratamentos de casos clínicos, cuja percentagem foi de $7 \%$ das vacas em lactação. O impacto da mastite foi estimado como sendo o total de perdas acrescido das despesas com prevenção e tratamento de casos clínicos. O aumento da taxa de descarte influenciou diretamente no impacto econômico da mastite. O elevado impacto econômico evidencia a necessidade de monitoramento da doença, para diminuírem os prejuízos causados pela mesma. As despesas com tratamento preventivo representaram, no máximo, 9,2\% do impacto econômico, o que demonstra vantagem em investir nessa prática, pois ela irá contribuir significativamente para diminuição da contagem de células somáticas no tanque e, consequentemente, para reduzir o impacto econômico da mastite.
\end{abstract}

Termos para indexação: Bovinocultura leiteira, economia, sanidade animal, simulação.

\section{ABSTRACT}

The objectives of this research were to analyze and quantify the influence of the percentage of involuntary culling of matrices on the economic impact of mastitis in dairy herd. The work was conducted by means of a simulation in the CU\$TO MASTITE software, taking into account dairy herds with culling rates of 2, 4 and $6 \%$. The expenditures on monitoring were considered as prevention (culture and ambiogram, bulk tank somatic cell count and individual somatic cell count) pre- and post-dipping, vaccination, treatment of dry cows and maintenance of milking machine. As curative measurements, the treatments of clinical cases (7\% of the lactating cows) were considered. The impact of mastitis was estimated as being the total of losses plus expenses with prevention and treatment of clinical cases. The increase of culling rate influenced directly the economic impact of mastitis. The elevated economic impact stresses the need for monitoring the disease to decrease loss. The expenses on preventive treatment account a maximum $9.2 \%$ of the economic impact, which demonstrates the advantages of investing in that practice, which it will contribute significantly towards the decrease of the bulk tank somatic cell count and thus reducing the economic impact of mastitis.

Index terms: Animal health, dairy cattle, saving, simulation.

(Recebido em 14 de abril de 2010 e aprovado em 14 de setembro de 2010)

\section{INTRODUÇÃO}

O descarte de vacas leiteiras é uma prática complexa e depende dos objetivos da propriedade, havendo a necessidade de se considerar a idade da vaca, o estágio de lactação, o histórico, a sanidade, o nível de produção de leite e a performance reprodutiva (Santos et al., 2001). Cardoso et al. (1999) consideram descartes voluntários de até $10 \%$ como níveis ótimos quando existe venda de animais para outros rebanhos.

Santos et al. (2001) salientaram que a taxa de descarte de novilhas acima de $30 \%$ exige uma grande disponibilidade de novilhas para reposição, o que representou um custo total de $15 \%$ a $20 \%$ da atividade leiteira. Tal fato pode aumentar os custos ou diminuí-los se conseguir baixar a idade do primeiro parto, conseguindo, assim, disponibilidade de novilhas para comercialização.

A reposição de animais de qualidade de um plantel representa parte importante dos custos de produção do sistema. Vários pesquisadores têm relatado a importância do tema e atribuído diferentes fatores ao descarte de vacas leiteiras, dentre os quais podem ser citados: a conformação de úbere e tetos e ocorrência de mastite (O’Bleness \& ¥an $¥$ ¥leck, 1962; Andrus et al., 1970; Burnside, 1971; Allaire, 1981; Congleton \& King, 1984; Seegers et al., 2003).

${ }^{1}$ Universidade Federal de Lavras/UFLA - Departamento de Medicina Veterinária/DMV - Lavras, MG

2Universidade Federal de Lavras/UFLA - Departamento de Medicina Veterinária/DMV - Cx. P. 3037 - 37200-000 - Lavras, MG - malopes@dmv.ufla.br 
A mastite é a doença responsável por grande parte dos descartes em um plantel. Nos Estados Unidos, estimase que $26,9 \%$ dos descartes seja por problemas de úbere e mastite (United States of America, 2002). Esses resultados comprometem a longevidade dos animais, levando muitas vezes a descarte de animais de grande pontencial, majorando os custos e levando à aceleração da taxa de reposição do plantel. Peller et al. (1999) verificaram que $63 \%$ das fazendas realizam descarte por mastite. Segundo Silva et al. (2004), em animais da raça holandesa os descartes devido a alterações na glândula mamária representaram $18,63 \%$, sendo a mastite a maior causa representando $56,82 \%$.

A reposição dos animais é sem dúvida muito importante, mas busca-se, em especial, alta taxa de descarte voluntário, porque irá valorizar melhor o animal descartado e possibilitar a escolha dos animais que permanecerão no plantel, promovendo aumento de produção e incremento genético no plantel.

Considerando os aspectos apresentados, bem como a importância do tema realizou-se esta pesquisa, cujo objetivo foi analisar e quantificar a influência do descarte involuntário de matrizes no impacto econômico da mastite em rebanhos leiteiros.

\section{MATERIAL E MÉTODOS}

A pesquisa foi conduzida no Laboratório de Informática Aplicada, do Departamento de Medicina Veterinária da Universidade Federal de Lavras (UFLA), por meio de simulação de dados, utilizando o sistema computacional "CUSTO MASTITE". Os fatores utilizados com os seus respectivos valores foram: percentual de casos clínicos (7\%); percentual de vacas secas (33\%); quantidade de vacas em lactação (100 vacas); frequência de ordenhas/ dia (2); intervalo de partos (15 meses); contagem de células somáticas $(500.000$ células somáticas $/ \mathrm{mL})$; quartos acometidos clinicamente (1); quantidade de doses de vacina para vaca seca (3); produtividade diária (20 kg/vaca/ dia); percentuais de morte em virtude da mastite/ano (1\%); valor de aquisição da vaca $(\mathrm{R} \$ 3.000,00)$ e o valor da vaca a ser descartada $(\mathrm{R} \$ 1.314,00)$.

Para avaliar o impacto do descarte involuntário devido à mastite consideraram-se as taxas de $2 \%, 4 \%$ e $6 \%$ do descarte total do rebanho. Esses dados foram selecionados a partir dos resultados obtidos nos estudos de Silva et al. (2008) e O'Bleness \& Yleck (1962), respectivamente, para taxas de descarte de $10 \%$ e $20 \%$ do descarte total realizado por diferentes causas. Adotou-se, também, a taxa de descarte de $30 \%$, resultado da pesquisa de Jones (1999), o qual relatou que em rebanhos com altas CCST ocorreram descartes maiores, próximo a $29 \%$.
As despesas com tratamento curativo envolveram aquelas com casos clínicos subagudos e agudos, considerando-se, neste estudo os valores de $75 \%$ e $25 \%$ respectivamente. A quantidade total de casos clínicos por mês foi obtida através da fórmula proposta por Santos \& Fonseca (2007):

$\%$ de mastite clínica do mês $=\frac{(\text { dias de mastite clínica/dias do mês }) \times 100}{n^{\circ} \text { médio de vacas em lactação }}$

O valor obtido foi multiplicado pela quantidade de meses do ano, estimando, assim, a quantidade de casos clínicos por ano.

Custo operacional efetivo (COE) do tratamento curativo (caso subagudo+agudo)/vaca em lactação/ano = (valor de tratamento de casos clínicos subagudos no ano + valor de tratamento de casos clínicos agudos no ano)/ quantidade de vacas em lactação.

$\mathrm{O}$ valor atribuído ao $\mathrm{kg}$ de leite comercializado foi de R \$0,67, obtido na Cooperativa Agrícola Alto Rio Grande, no município de Lavras, no mês de novembro de 2008. O valor considerado para a conversão em dólar foi US\$1.00 igual a $\mathrm{R} \$ 2,25$.

Foram consideradas como prevenção as despesas com monitoramento (cultura e anbiograma, contagem de células somáticas no tanque (CCST) e contagem de células somáticas individual (CCSI), pré e pós dipping, vacinação, tratamento de vacas secas e manutenção de ordenhadeira. Como medidas curativas, consideraram-se apenas os tratamentos com casos clínicos, cuja percentagem foi de $7 \%$ das vacas em lactação.

O impacto da mastite (IM) foi considerado como sendo:

- $\mathrm{IM}=$ Total em perdas + tratamento preventivo + tratamento curativo, em que:

- Total de perdas = perdas em leite (redução na produção e descarte de leite durante o tratamento e período de carência do antibiótico);

- Tratamento preventivo $=$ despesas com antibiograma e cultura + CCST + CMT + pré-dipping + pós-dipping + tratamento de vacas secas + vacinação de vacas secas;

- Tratamento curativo $=$ despesas com aplicação do antibiótico local + antibiótico sistêmico + antiinflamatório.

As perdas de leite foram quantificadas a partir de regressão linear:

$\bullet y=-4,7908+0,0226 x$, na qual "y" é a porcentagem de perda de leite e " $\mathrm{x}$ " a contagem de células somáticas. 


\section{RESULTADOS E DISCUSSÃO}

A avaliação do impacto econômico anual da mastite, por kg de leite, vaca em lactação e rebanho (vacas em lactação + vacas secas), em reais ( $R$ \$), em função de diferentes taxas de descarte pode ser observada na Tabela 1. Os impactos econômicos totais da mastite, em um ano, foram de $\mathrm{R} \$ 155.997,06$; $\mathrm{R} \$ 160.481,82$ e $\mathrm{R} \$ 164.966,58$, nos rebanhos com taxas de descarte involuntário de $2 \%, 4 \%$ e $6 \%$ respectivamente. Tomando-se por referência uma vaca em lactação, variou de $\mathrm{R} \$ 1.559,97$ a $\mathrm{R} \$ 1.649,67$ e de $\mathrm{R} \$ 0,2688$ a R $\$ 0,2843 / \mathrm{kg}$ de leite, nos rebanhos com descarte de $2 \%$ e $6 \%$ respectivamente (Tabela 1). As diferenças foram em virtude da quantidade de animais $(2,66 ; 5,32 ; 7,98)$ cronicamente acometidos descartados, o que ocasionou maior desvalorização de matrizes, elevando os valores das perdas e, consequentemente, o impacto econômico total por vaca em lactação e por kg de leite comercializado. A diferença de R $\$ 89,70$ (US\$39,86) do impacto econômico por vaca em lactação, ocasionada pela redução na taxa de descarte de 6\% para $2 \%(\mathrm{R} \$ 1.559,97$ - $\mathrm{R} \$ 1.649,67)$ mostra a necessidade da concentração de esforços para reduzi-la, visando aumentar a rentabilidade do sistema de produção, uma vez que em um rebanho de 100 vacas em lactação, isso representa uma perda de $\mathrm{R} \$ 8.970,00 /$ ano.

Indexado ao dólar americano, o impacto econômico por vaca em lactação/ano foi estimado em US\$693,32 a US\$733,19 nos rebanhos com taxas de descarte involuntário de $2 \%$ e $6 \%$ respectivamente. Esses valores foram bastante superiores aos obtidos por Holanda Junior et al. (2005) (US\$126,00). No entanto, esses pesquisadores não consideraram a mortalidade de vacas devido a mastite, não mencionaram o nível de CCST e não detalharam o que foi utilizado no item prevenção. Tais fatos podem justificar valores tão diferentes.

Tabela 1 - Avaliação do impacto econômico da mastite por kg de leite, vaca em lactação e rebanho (vacas em lactação + vacas secas), em $\mathrm{R}$, em função de diferentes taxas de descarte, em virtude de mastite, em rebanhos de 100 vacas holandesas em lactação, com produção diária de $20 \mathrm{~kg}$.

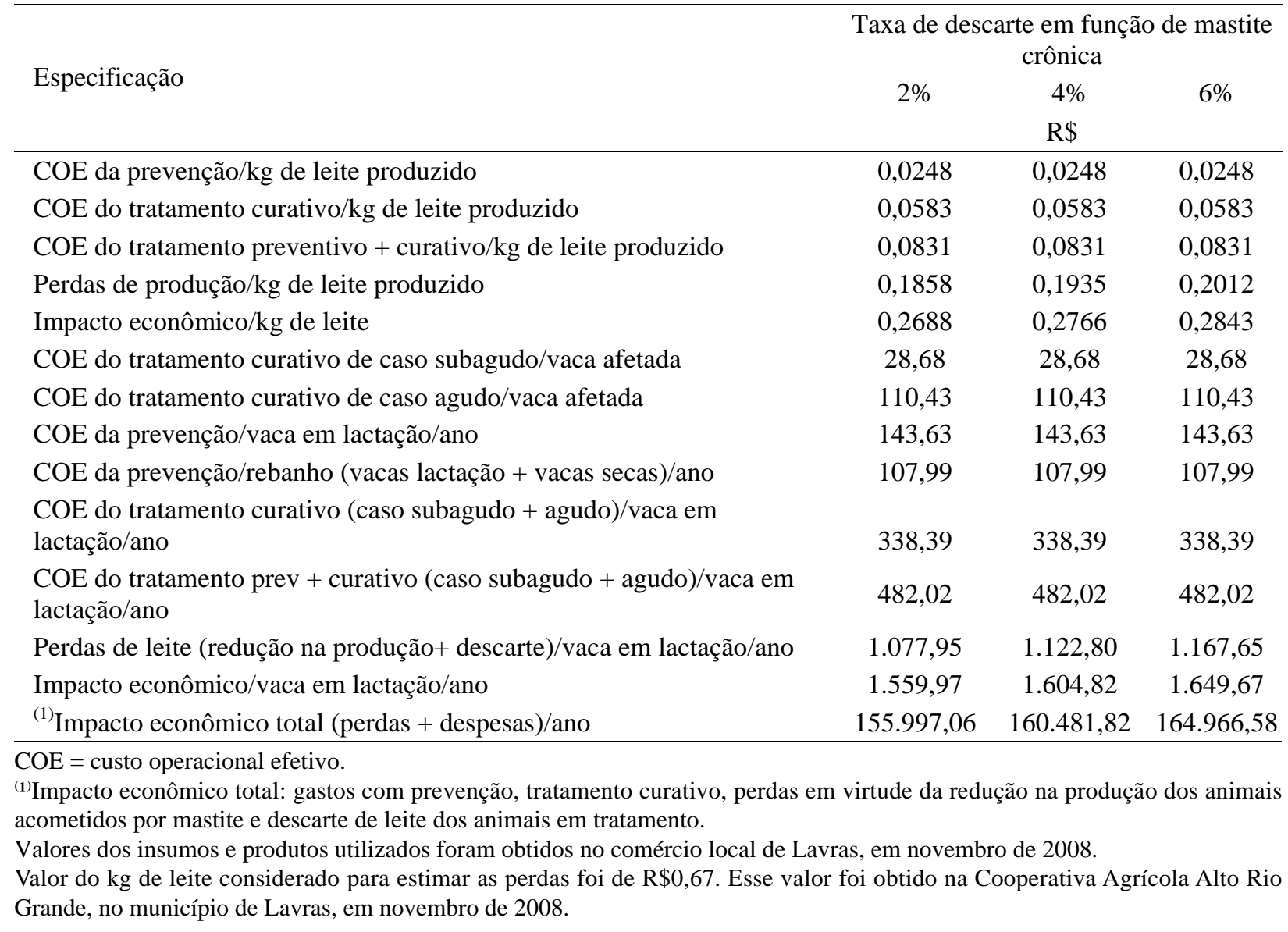


As perdas de produção (descarte de leite de animais em tratamento, diminuição na produção, desvalorização e morte de matrizes), por $\mathrm{kg}$ de leite, foram de $\mathrm{R} \$ 0,1858$; $\mathrm{R} \$ 0,1935$ e $\mathrm{R} \$ 0,2012 \mathrm{~kg} / \mathrm{leite}$ (Tabela 1 ), para as taxas de descarte de $2 \%, 4 \%$ e $6 \%$ respectivamente. As diferenças foram devidas à maior desvalorização de matrizes.

$\mathrm{O}$ custo operacional efetivo das medidas de prevenção, por $\mathrm{kg}$ de leite, foi de $\mathrm{R} \$ 0,0248 / \mathrm{kg}$; e de $\mathrm{R} \$ 0,0583 / \mathrm{kg}$ paras as medidas curativas, em todas as taxas de descarte estudadas. A prevenção por vaca em lactação/ ano, de R $\$ 143,63$ (US\$63,84), foi inferior ao custo com tratamento curativo, de $\mathrm{R} \$ 338,39$ (US $\$ 150,40$ ). O tratamento curativo de uma vaca com mastite apresentando sintomas clínicos da doença foi de $\mathrm{R} \$ 28,68$ (US\$12,75), para cada caso subagudo e de R $\$ 110,43$ (US\$49,08), para casos considerados agudos (Tabela 1). Para a estimativa de casos subagudos, foram consideradas as despesas com o tratamento por meio da soma dos antibióticos locais aplicados (três dias) e mão-de-obra utilizada para realizar essa atividade (10 minutos por teto acometido, com valor unitário de $\mathrm{R} \$ 0,04)$. O valor estimado para caso agudo resultou da soma dos gastos para tratamento local e sistêmico por um período de cinco dias. Foram considerados os valores com mão-de-obra, seringa e agulha para realização do tratamento sistêmico. Os valores foram superiores aos $\mathrm{R} \$ 24,55$ encontrados por Costa et al. (2005), que não mencionaram se esses foram para casos subagudos ou agudos. O custo do tratamento curativo de uma vaca em lactação/ano foi estimado em $\mathrm{R} \$ 338,39$ (US\$150,40), para todos os casos estudados, valor que foi superior aos $\mathrm{R} \$ 143,63$ das despesas com prevenção por vaca em lactação/ano.

$\mathrm{O}$ fato das medidas preventivas apresentarem valores tão inferiores aos tratamentos curativos, em todos os casos, demonstra que aquelas, que muitos julgam serem onerosas, trabalhosas e desnecessárias, mostram-se de excelente relação custo/benefício.

Não houve diferença nos valores do $\mathrm{kg}$ de leite para prevenção e tratamento curativo, porque a quantidade de vacas secas e em lactação foi a mesma (50 e 100) nos três rebanhos analisados, bem como a quantidade de casos clínicos (751) e produtividade diária/animal (20 kg). Os valores de tratamento curativo por kg de leite, preventivo + curativo por kg de leite, COE do tratamento curativo de casos subagudos e agudo por vaca afetada, custo da prevenção por vaca em lactação, COE da prevenção por vaca do rebanho, custo do tratamento curativo por vaca em lactação/ano, também não tiveram nenhuma alteração, porque os mesmos não são influenciados pela taxa de descarte. Na Tabela 2, pode-se observar que o percentual do item prevenção apresentou diminuição à medida que aumentou a taxa de descarte. Vale salientar que o valor absoluto empregado na prevenção, de $\mathrm{R} \$ 14.362,55$, não se alterou em nenhum dos casos estudados. Essa mudança no percentual foi devida à desvalorização de matrizes, em virtude do descarte em consequência de casos de mastite crônica, afetando diretamente a produtividade e rentabilidade da propriedade.

A prevenção é um item que deve receber grande atenção por parte dos técnicos e pecuaristas. Como pode ser observado na Tabela 2 esse item só não foi inferior às perdas com morte e desvalorização de matrizes em todas as taxas de descarte estudadas. Tais valores evidenciam a importância de se investir em medidas preventivas, que incluam não somente os tratamentos preventivos, como também medidas de manejo, principalmente na ordenha, além de boas condições de higiene nas instalações, visando diminuir novas infecções. Infelizmente, tal prática, de acordo com Lopes et al. (2004), que verificaram que cuidados com a obtenção higiênica do leite têm sido negligenciados por parcela significativa de produtores de leite, pois, ao fazerem o levantamento de todas as despesas operacionais efetivas em 16 propriedades leiteiras do sul de Minas Gerais, constataram que em 50\% não houve nenhuma despesa com aquisição de soluções pré e pós dipping, detergentes ácidos e alcalinos, papel toalha, desinfetantes de demais produtos utilizados na ordenha.

As perdas por descarte de leite tiveram as maiores representatividades, sendo responsáveis por até 43,9\% do impacto econômico causado pela mastite, em virtude do alto descarte de leite de animais clinicamente acometidos pela doença e em tratamento. A soma do descarte de leite com a redução na produção irá resultar em 64,$3 ; 62,5 \%$ e $60,8 \%$ do impacto total, o que foi abaixo dos resultados de Hoblet et al. (1991), citados por Degraves \& Fetrow (1993) que estimou as perdas desses dois itens em $85 \%$.

A questão relacionada ao descarte do leite, item de grande importância no impacto econômico da mastite, ainda se torna um agravante maior, quando se analisa a questão de poluição ambiental. A resolução CONAMA n 357/2005, no capítulo IV, artigo 24 estabelece que "os efluentes de qualquer fonte poluidora somente poderão ser lançados, direta ou indiretamente, nos corpos de água, após o devido tratamento e desde que obedeçam às condições, padrões e exigências dispostos" (Brasil, 2005); uma vez que não há uma utilização racional recomendada. Pesquisadores têm recomendado estudos adicionais, com relação à utilização desse leite para o aleitamento artificial de bezerros, o que 
Tabela 2 - Itens que compõem o impacto econômico anual da mastite, em $\mathrm{R} \$$ e percentagem, em função de diferentes taxas de descarte, em rebanhos de 100 vacas holandesas em lactação, com produção diária de $20 \mathrm{~kg}$.

\begin{tabular}{|c|c|c|c|}
\hline \multirow{3}{*}{ Especificação } & \multicolumn{3}{|c|}{ Taxa de descarte em função de mastite crônica } \\
\hline & $2 \%$ & $4 \%$ & $6 \%$ \\
\hline & \multicolumn{3}{|c|}{$\mathrm{R} \$ \mathrm{e} \%$} \\
\hline \multicolumn{4}{|l|}{ Despesas } \\
\hline Despesas com tratamento preventivo & $14.362,55(9,2)$ & $14.362,55(8,9)$ & $14.362,55(8,7)$ \\
\hline Despesas com tratamento curativo* & $33.839,25(21,7)$ & $33.839,25(21,1)$ & $33.839,25(20,5)$ \\
\hline Despesas totais (sub total) & $48.201,80(30,9)$ & $48.201,80(30,0)$ & $48.201,80(29,2)$ \\
\hline \multicolumn{4}{|l|}{ Perdas } \\
\hline Morte de matrizes & $3.000,00(1,9)$ & $3.000,00(1,9)$ & $3.000,00(1,8)$ \\
\hline Desvalorização de matrizes & $4.484,76(2,9)$ & $8.969,52(5,6)$ & $13.454,28(8,2)$ \\
\hline $\begin{array}{l}\text { Descarte de leite de animais em } \\
\text { tratamento }\end{array}$ & $68.474,00(43,9)$ & $68.474,00(42,7)$ & $68.474,00(41,5)$ \\
\hline Redução na produção de leite & $31.836,49(20,4)$ & $31.836,50(19,8)$ & $31.836,50(19,3)$ \\
\hline${ }^{(1)}$ Perdas Totais (sub total) & $107.795,26(69,1)$ & $112.280,02(70,0)$ & $116.764,78(70,8)$ \\
\hline (2) Impacto econômico total & $155.997,06(100,0)$ & $160.481,82(100,0)$ & $164.966,58(100,0)$ \\
\hline
\end{tabular}

era uma prática recomendada há alguns anos. Batista et al. (2008) verificaram que o aleitamento de bezerras com o leite de vacas em tratamento com mastite pode resultar em bactérias patogênicas mais resistentes e na diminuição da flora protetora, levando à diminuição das respostas imunológicas e, talvez, à maior quantidade de casos de criptosporidiose.

A desvalorização de matrizes acometidas por mastite crônica, devido ao descarte involuntário, representou $2,9 \%$ a $8,2 \%$ do impacto total, de acordo com a taxa de descarte estudada (Tabela 2). A desvalorização dos animais é um item que onera o produtor, pois, a cada animal descartado, haverá necessidade de investimentos para reposição.

O descarte por problemas de saúde de úbere tem sido apontado por vários pesquisadores como a terceira maior causa de descarte, sendo inferior somente à baixa produção de leite e problemas reprodutivos, variando de $18 \%$ a $26 \%$ (Norman et al., 1978; United States of America, 2002). Entretanto, o fato de um animal ter uma baixa produção leiteira pode ser em virtude de casos de mastite subclínica não identificada, ocasionando descarte errôneo de uma vaca de alto potencial, aumentando o descarte por baixa produção e subestimando aquele em função da mastite. O National Mastitis Council-NMC (1996) estima uma redução na produção de até $29 \%$, devido a contagem de células somáticas no tanque, em decorrência da mastite subclínica e Degraves \& Fetrow (1993) atribuíram à mastite clínica uma redução de $11 \%$ na produção de leite durante a lactação.

A receita bruta foi de $\mathrm{R} \$ 392.284,74 ; \mathrm{R} \$ 395.779,98 \mathrm{e}$ $\mathrm{R} \$ 399.275,22$, o que correspondeu à soma dos valores apurados com a venda de leite $(99,11 \% ; 98,22 \%$ e $97,30 \%)$ e animais $(0,89 \% ; 1,78 \%$; e $2,70 \%)$; para taxas de descarte de $2 \% ; 4 \%$ e $6 \%$ respectivamente. O impacto econômico total da mastite resultou em $39,77 \%$; 40,55\% e $41,32 \%$, em relação a renda bruta, para as mesmas taxas de descarte estudadas. Quanto a venda de animais, não há menção na literatura de qual percentual seria o ideal para esses valores. No entanto, essas estimativas são pequenas, quando comparadas aos valores obtidos por Lopes et al. (2008), que encontraram 7,55\%; 16,26\% e 3,14\% e Lopes et al. (2006), que foi de $20,29 \% ; 7,29 \%$ e $9,70 \%$ para pequenos, médios e grandes produtores. A diferença dos percentuais se deve ao fato de que, neste estudo, foi considerado somente o descarte involuntário por mastite, enquanto nos 
outros estudos mencionados foram considerados todas as vendas de animais, o que possibilita maior receita. Lopes et al. (2009a) encontraram $15 \%$ a $20 \%$ da receita bruta proveniente da venda de animais, o que também está bem acima dos resultados observados neste estudo.

A renda bruta proveniente da venda dos animais aumentou à medida que o descarte aumentou. Tal fato ocorreu em virtude da maior quantidade de animais comercializados $(2,66 ; 5,32$ e 7,98). Apesar de, em um primeiro momento, o aumento da receita parecer uma vantagem quando se tem aumento da taxa de descarte, quando é realizada uma análise detalhada sobre os impactos, verifica-se que esse aumento é justamente em virtude da maior desvalorização de matrizes devido ao descarte involuntário ( $\mathrm{R} \$ 4.484,76$; $\mathrm{R} \$ 8.969,52$ e $\mathrm{R} \$ 13.454,28$ ) o que resultou em $2,9 \% ; 5,6 \%$ e $8,2 \%$ do impacto total para taxas de descarte de $2 \%, 4 \%$ e $6 \%$ respectivamente. A desvalorização dos animais é um item que onera o produtor, uma vez que, a cada animal descartado, haverá necessidade de investimento para reposição. Lopes et al. (2009b) verificaram que a desvalorização das vacas descartadas involuntariamente é bastante acentuada, uma vez que as fêmeas que não estavam nesse grupo renderam uma receita de $\mathrm{R} \$ 2.680,00$; as fêmeas comercializadas devido descarte involuntário, dos quais os pesquisadores citam problemas mamários, auferiram uma receita de somente $\mathrm{R} \$ 882,00 /$ vaca, o que representa $67,09 \%$ de desvalorização. Valores tão baixos se devem ao fato que esses animais são comercializados pelo valor pago por arroba da vaca gorda, enquanto as vacas oriundas de descarte voluntário são animais eliminados de um rebanho e vendidos para outro, pois ainda possuem capacidade produtiva. Aliado a esse fato, tem-se ainda a questão de que haverá maior tempo para que ocorra a evolução e a estabilização do rebanho. Com isso, as benfeitorias e outros bens depreciáveis ficarão parcialmente ociosos, o que eleva o custo de produção. Lopes et al. (2009a) afirmaram que quanto menor a taxa de descarte, menor será a seleção de matrizes, resultando em menores ganhos genéticos e comprometendo aumentos da produtividade. Ao estudarem a influência do impacto econômico no intervalo de partos, Lopes et al. (2009b) alertam que intervalos de partos muito longos afetam a composição do rebanho e, com isso, haverá uma menor quantidade de novilhas para reposição, o que poderá afetar o melhoramento genético do rebanho, além de diminuir as receitas auferidas com a venda de animais.

As perdas totais apresentaram o maior impacto percentual, em relação à receita bruta do sistema de produção, sendo de $27,48 \% ; 28,37 \%$ e $29,24 \%$, para taxas de descarte de $2 \% ; 4 \%$ e $6 \%$ respectivamente. Essas foram compostas por: morte de matrizes $(0,76 \% ; 0,76 \%$ e $0,75 \%)$; desvalorização de matrizes $(1,14 \% ; 2,27 \%$ e $3,37 \%)$; descarte de leite de animais em tratamento $(17,46 \% ; 17,30 \%$; e $17,15 \%)$; redução na produção $(8,12 \% ; 8,04 \%$; e $7,97 \%)$, para taxas de descarte de $2 \% ; 4 \%$ e $6 \%$ respectivamente. As perdas por descarte de leite tiveram as maiores representatividades, sendo responsáveis por até $43,9 \%$ do impacto econômico causado pela mastite, em virtude do alto descarte de leite de animais acometidos pela doença e período de carência do medicamento utilizado no tratamento.

Os percentuais de prevenção, em relação a receita bruta foram estimados em $3,66 \% ; 3,63 \%$ e $3,60 \%$, enquanto que os referentes ao tratamento curativo em $8,63 \% ; 8,55$ e $8,48 \%$, para taxas de descarte de $2 \%$; $4 \%$ e $6 \%$ respectivamente.

\section{CONCLUSÕES}

$\mathrm{O}$ aumento da taxa de descarte influenciou diretamente no impacto econômico da mastite. $\mathrm{O}$ elevado impacto econômico evidencia a necessidade de monitoramento da doença, para diminuir os prejuízos causados pela mesma. Esforços devem ser concentrados no intuito de reduzir a taxa de descarte, em virtude da mastite, uma vez que essa redução, aumentará os descartes voluntários, possibilitando maior eficácia no programa de melhoramento genético da propriedade $\mathrm{e}$ aumento da receita auferida com a comercialização de animais.

As despesas com tratamento preventivo representaram, no máximo, 9,2\% do impacto econômico, o que demonstra vantagem em se investir nessa prática, pois ela irá contribuir significativamente para diminuição da contagem de células somáticas no tanque e, consequentemente, para reduzir o impacto econômico da mastite.

\section{REFERÊNCIAS BIBLIOGRÁFICAS}

ALLAIRE, F.R. Economic consequences of replacing cows with genetically improved heifers. Journal of Dairy Science, Champaign, v.64, n.10, p.1985-1995, Oct. 1981.

ANDRUS, D.F.; FREEMAN, A.E.; EASTWOOD, B.R. Age distribution and herd life expectancy in iowa dairy herds. Journal of Dairy Science, Champaign, v.53, n.6, p.764-771, June 1970. 
BATISTA, C.G.; COELHO, S.G.; RABELO, E.; LANA, A.M.Q.; CARVALHO, A.U.; REIS, R.B.; SATURNINO, H.M. Desempenho e saúde de bezerras alimentadas com leite sem resíduo de drogas antimicrobianas ou leite de vacas tratadas contra mastite adicionado ou não de probiótico. Arquivo Brasileiro de Medicina Veterinária e Zootecnia, Belo Horizonte, v.60, n.1, p.185-191, jan./fev. 2008.

BRASIL. Ministério do Meio Ambiente. Conselho Nacional do Meio Ambiente. Resolução no 357, de 17 de março de 2005. Dispõe sobre a classificação dos corpos de água e diretrizes ambientais para o seu enquadramento, bem como estabelece as condições e padrões de lançamento de efluentes. Brasília, 2005. Disponível em: ¿http://portal.saude.gov.br/portall arquivos/pdf $/$ resolucao_conama_357.pdf $>$. Acesso em: 5 mar. 2009.

BURNSIDE, E.B. Cow-indexing for potential procedure and culling levels dams of dairy bulls. Journal of Dairy Science, Champaign, v.53, n.2, p.195-199, Feb. 1971.

CARDOSO, V.L.; NOGUEIRA, J.R.; ARENDONK, J.A.M. van. Optimum replacement and insemination policies for Holstein cattle in the Southeastern region of Brazil: the effect of selling animals for production. Journal of Dairy Science, Champaign, v.82, p.14491458, 1999.

CONGLETON, W.R.; KING, L.W. Profitability of dairy cow herd life. Journal of Dairy Science, Champaign, v.67, n.3, p.661-674, Mar. 1984.

COSTA, E.O.; MOTA, R.; SANTOS, F.G.B. Contagem de células somáticas de amostras de leite de glândulas mamárias de fêmeas bovinas em lactação infectadas por microrganismos dos gêneros Streptococcus,

Staphylococcus e Corynebacterium. Revista Napgama, São Paulo, v.8, n.2, p.3-7, 2005.

DEGRAVES, F.J.; FETROW, J. Economics of mastitis and mastitis control. Veterinary Clinics of North America: Food Animal Practice, Philadelphia, v.9, n.3, p.421-434, Nov. 1993.

HOLANDA JUNIOR, E.V.; MADALENA, F.E.; HOLANDA, E.D.; MIRANDA, W.M.; SOUZA, M.R. Impacto econômico da mastite em seis fazendas de
Araxá, Minas Gerais, Brasil. Archivos Latinoamericanos de Produção Animal, Caracas, v.13, n.2, p.63-69, 2005.

JONES, G.M. Guidelines to culling cows with mastitis. Virginia: Virginia Cooperative Estension, 1999. 4p.

LOPES, M.A.; CARDOSO, M.G.; CARVALHO, F. de M.; LIMA, A.L.R.; DIAS, A.S.; CARMO, E.A. do. Efeito da escala de produção nos resultados econômicos de sistema de produção de leite na região de Lavras (MG) em 2004 e 2005. Archivos Latinoamericanos de

Producción Animal, Caracas, v.16, n.3, p.121-129, 2008.

LOPES, M.A.; CARDOSO, M.G.; DEMEU, F.A. Influência de diferentes índices zootécnicos na composição e evolução de rebanhos bovinos leiteiros.

Ciência Animal Brasileira, Goiânia, v.10, n.2, p.446-453, abr./jun. 2009a.

LOPES, M.A.; DEMEU, F.A.; SANTOS, G.; CARDOSO, M.G. Impacto econômico do intervalo de partos em rebanhos bovinos leiteiros. Ciência e Agrotecnologia, Lavras, v.33, 2009b. Suplemento.

LOPES, M.A.; LIMA, A.L.R.; CARVALHO, F. de M.; REIS, R.P.; SANTOS, I.C.; SARAIVA, F.H. Efeito da escala de produção nos resultados econômicos de sistemas de produção de leite na região de Lavras (MG): um estudo multicasos. Boletim da Indústria Animal, Nova Odessa, v.63, n.3, p.177-188, 2006.

LOPES, M.A.; LIMA, A.L.R.; CARVALHO, F. de M.; REIS, R.P.; SANTOS, I.C.; SARAIVA, F.H. Efeito do tipo de sistema de criação nos resultados econômicos de sistemas de produção de leite na região de Lavras, MG. Ciência e Agrotecnologia, Lavras, v.28, n.5, p.1177-1189, set./out. 2004.

NATIONAL MASTITIS COUNCIL. Current concepts of bovine mastitis. 4.ed. Madison, 1996. 64p.

NORMAN, H.D.; CASSELL, B.G.; DICKINSON, F.N. Phenotypic and genetic relationships between type classification traits in jerseys. Journal of Dairy Science, Champaign, v.61, n.91, p.1250-1256, 1978.

O’BLENESS, G.V.; ¥LECK, L.D. van. Reasons for disposal of dairy cows from New York herds. Journal of Dairy Science, Champaign, v.45, n.9, p.1087-1093, Mar. 1962. 
SANTOS, G.T.; CAVALIERI, F.L.B.; MASSUDA, E.M. Alguns aspectos econômicos e de manejo na criação de novilhas leiteiras. Revista Balde Branco, São Paulo, v.37, n.474, p.56-60, maio 2001.

SANTOS, M.V.; FONSECA, L.F.L. Estratégias para controle de mastite e melhoria da qualidade do leite. São Paulo: Manole, 2007. 313p.

SEEGERS, H.; FOURICHON, C.; BEAUDEAU, F. Production effects related to mastitis and mastitis economics in dairy cattle herds. Veterinary Research, Chicago, v.34, n.5, p.475-491, Sept./Oct. 2003.

SILVA, L.A.F.; SILVA, E.B. da; ROMANI, A.F.; GARCIA, A.M. Causas de descarte de fêmeas bovinas leiteiras adultas. Revista Brasileira de Saúde e Produção Animal, Salvador, v.5, p.9-17, 2004.

SILVA, L.A.F.; COELHO, K.O.; MACHADO, P.F.; SILVA, M.A.M.; MOURA, M.I.; BARBOSA, V.T.; GOULART, M.M.; GOULART, D.S. Causas de descarte de vacas da raça holandesa confinadas em uma população de 2.083 bovinos: 2000-2003. Ciência Animal Brasileira, Goiânia, v.9, n.2, p.383-389, abr./jun. 2008.

UNITED STATES OF AMERICA. United States Department of Agriculture. Dairy 2002: part I: reference of dairy health and management in the United States. Fort Collins, 2002. 92p. 